\title{
Neuropeptides in the posterodorsal medial amygdala modulate central cardiovascular reflex responses in awake male rats
}

\author{
E. Quagliotto ${ }^{1,2}$, K.R. Casali ${ }^{3}$, P. Dal Lago ${ }^{4}$ and A.A. Rasia-Filho ${ }^{1,2}$ \\ ${ }^{1}$ Departamento de Ciências Básicas da Saúde/Fisiologia, Universidade Federal de Ciências da Saúde de Porto Alegre, \\ Porto Alegre, RS, Brasil \\ ${ }^{2}$ Programa de Pós-Graduação em Neurociências, Universidade Federal do Rio Grande do Sul, Porto Alegre, RS, Brasil \\ ${ }^{3}$ Instituto de Ciência e Tecnologia, Universidade Federal de São Paulo, São José dos Campos, SP, Brasil \\ ${ }^{4}$ Departamento de Fisioterapia, Universidade Federal de Ciências da Saúde de Porto Alegre, Porto Alegre, RS, Brasil
}

\begin{abstract}
The rat posterodorsal medial amygdala (MePD) links emotionally charged sensory stimuli to social behavior, and is part of the supramedullary control of the cardiovascular system. We studied the effects of microinjections of neuroactive peptides markedly found in the MePD, namely oxytocin (OT, $10 \mathrm{ng}$ and $25 \mathrm{pg} ; \mathrm{n}=6 / \mathrm{group})$, somatostatin (SST, 1 and $0.05 \mu \mathrm{M}$; $\mathrm{n}=8$ and 5, respectively), and angiotensin II (Ang II, $50 \mathrm{pmol}$ and $50 \mathrm{fmol} ; \mathrm{n}=7 / \mathrm{group}$ ), on basal cardiovascular activity and on baroreflex- and chemoreflex-mediated responses in awake adult male rats. Power spectral and symbolic analyses were applied to pulse interval and systolic arterial pressure series to identify centrally mediated sympathetic/parasympathetic components in the heart rate variability (HRV) and arterial pressure variability (APV). No microinjected substance affected basal parameters. On the other hand, compared with the control data (saline, $0.3 \mu \mathrm{L} ; n=7$ ), OT (10 ng) decreased mean AP $\left(\mathrm{MAP}_{50}\right)$ after baroreflex stimulation and increased both the mean AP response after chemoreflex activation and the highfrequency component of the HRV. OT $(25 \mathrm{pg})$ increased overall HRV but did not affect any parameter of the symbolic analysis. SST $(1 \mu \mathrm{M})$ decreased MAP 50 , and SST $(0.05 \mu \mathrm{M})$ enhanced the sympathovagal cardiac index. Both doses of SST increased HRV and its low-frequency component. Ang II (50 pmol) increased HRV and reduced the two unlike variations pattern of the symbolic analysis $(P<0.05$ in all cases). These results demonstrate neuropeptidergic actions in the MePD for both the increase in the range of the cardiovascular reflex responses and the involvement of the central sympathetic and parasympathetic systems on HRV and APV.
\end{abstract}

Key words: Baroreceptor and chemoreceptor reflexes; Power spectral analysis; Symbolic analysis; Oxytocin; Somatostatin; Angiotensin II

\section{Introduction}

The posterodorsal medial amygdala (MePD) is a forebrain subcortical component of the "extended amygdala" (1) with a well-described role in the response to stressful stimuli (2), hypothalamic neuroendocrine secretion (3), and the display of social behaviors, such as aggressive and reproductive behaviors in rats $(4,5)$. The MePD is important for higher-level, supramedullary control of cardiovascular functions (6-8), and, in this sense, sends projections to the central amygdaloid nucleus (CeA) and then to the $\mathrm{A} 1$ noradrenergic cells of the caudal ventrolateral medulla and the nucleus of the solitary tract (NTS; 9,10). The MePD is also interconnected with other medial amygdala subnuclei that innervate cardiovascular-related areas of the hypothalamus $(9,10)$ and the sympathetic/parasympathetic-related parts of the periventricular hypothalamic zone (11). It is highly likely that this integrated network modulates cardiovascular responses to ensure appropriate hemodynamic responses concomitant with the expression of social behaviors $(7,8,12)$.

The involvement of the MePD in the regulation of heart rate $(\mathrm{HR})$ and arterial blood pressure (AP) were reported under different methodological conditions. For example, electrical stimulation of the MePD increased AP in mice (13). Activation of the whole mouse medial amygdala (MeA) after fear or aversive stress led to sympathetic activation

Correspondence: A.A. Rasia-Filho: <rasiafilho@pq.cnpq.br><aarf@ufcspa.edu.br>.

Received May 12, 2014. Accepted September 22, 2014. First published online November 21, 2014. 
and neurogenic hypertension $(14,15)$, whereas bilateral neurotoxic lesions of the posterior part of the $\mathrm{MeA}$ attenuated the development of high AP levels in spontaneously hypertensive rats (16). Moreover, central control of short-term reflexes of the cardiovascular system integrates inputs from peripheral baroreceptors and chemoreceptors and the sympathetic/parasympathetic output to the heart and vascular beds (17). Microinjection of glutamate $(2 \mu \mathrm{g} / 0.3 \mu \mathrm{L})$ into the MePD of awake rats elicits a selective activation of the central sympathetic adjustment to modulate the baroreflex response, whereas microinjection of gamma-aminobutyric acid (GABA; $61 \mathrm{ng} / 0.3 \mu \mathrm{L}$ ) activates the central parasympathetic counterpart (8). Histamine $(30 \mu \mathrm{g} / 0.3 \mu \mathrm{L}$ and $300 \mu \mathrm{g} / 0.3 \mu \mathrm{L}$ ) in the MePD shows more complex and dose-dependent responses, with a lower dose modulating part of the baroreflex response and a higher dose leading to a decrease in the parasympathetic component of the HR variability (HRV), an increase in the sympathetic/parasympathetic balance at basal conditions, and impairment of the chemoreflex bradycardic response (7).

It is notable that various neuroactive peptides can be found in the MePD. Oxytocin (OT)-binding sites occur in different MePD cellular columns (18), and local OT modulates the neural processing of social odorants and approach behavior (19). Somatostatin (SST) is found in the MePD as well $(20,21)$ and causes a dose-dependent inhibition of the rat MeA, either directly or by activating GABAergic synaptic transmission (21). There is also an evident expression of the angiotensin II (Ang II) 1A receptor in the MePD (22). These findings are worth noting because OT reduces cardiovascular responses to acute stress in rats (23) and modulates baroreceptor reflex responses (24). SST modulates sympathetic and parasympathetic cardiovascular actions and induces hypotension and bradycardia (25). Ang II can increase AP due to centrally mediated effects (26), acting in circumventricular organs or in the NTS, either by activating the central sympathetic nervous system or by elevating plasma vasopressin, noradrenaline, and adrenaline levels $(6,27)$. In rats, central Ang II also blunts parasympathetic activity, reduces baroreflex sensitivity (28), and stimulates chemoreflex responses (29). However, it is not currently known whether there are cardiovascular effects induced by these neuropeptides when acting in the rat MePD.

Here, we studied the basal hemodynamic state and reflex-mediated cardiovascular responses after microinjections of OT, SST, and Ang II into the MePD of awake male rats. Baroreflex and chemoreflex responses were tested. Power spectral and symbolic analyses were performed to evaluate the central involvement of sympathetic and parasympathetic components in the variability of the $\mathrm{HR}$ and AP. We used the same methodological approach previously described for the study of classical neurotransmitter actions in the MePD (7,8, and references therein) and found additional changes in the central control of cardiovascular reflexes elicited by these neuropeptides in this brain area, providing additional detail for better understanding of the mechanisms already described in the literature (6).

\section{Material and Methods}

\section{Animals}

Adult male Wistar rats (3-4 months old, body weight 250-300 g) were kept in groups under standard laboratory conditions, with food and water ad libitum and room temperature around $22^{\circ} \mathrm{C}$ in a $12: 12$-h light-dark cycle (lights off at 7:00 pm). All efforts were made to minimize the number of animals and their suffering. Rats were manipulated according to international laws for ethical care and use (European Communities Council Directive of 24 November $1986,86 / 609 / E E C)$, conforming to national guidelines, and experiments were approved by the Ethics Committee of Universidade Federal de Ciências da Saúde de Porto Alegre (protocol \#05/029).

\section{Implantation of the MePD cannula and vascular catheters for hemodynamic evaluation}

The experimental design is shown in Figure 1. Animals were anesthetized with a combination of ketamine and xylazine (90 and $10 \mathrm{mg} / \mathrm{kg}$, ip, respectively) and were stereotaxically implanted with a cannula $(0.6 \mathrm{~mm}$ outer diameter, OD) $2 \mathrm{~mm}$ above the right MePD, according to the following coordinates: $3.3 \mathrm{~mm}$ posterior to the bregma,
EXPERIMENTAL DESIGN

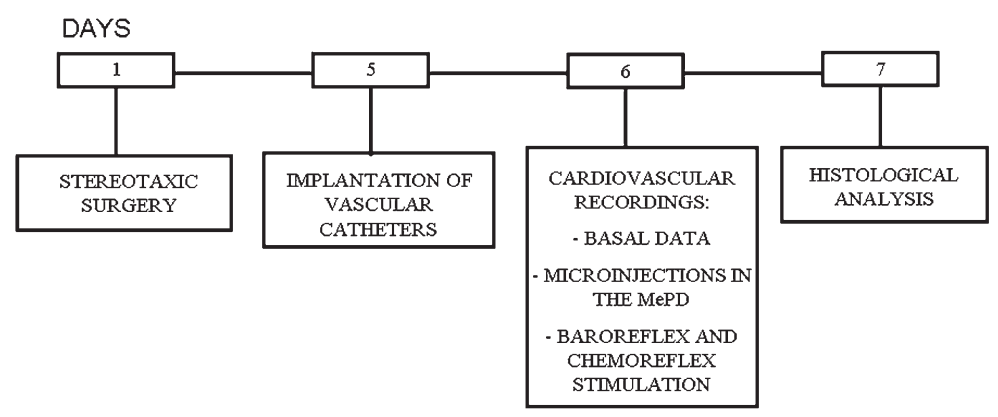

Figure 1. Experimental design (in days) with surgical, microinjection, cardiovascular recordings and histological procedure schedules. 
A

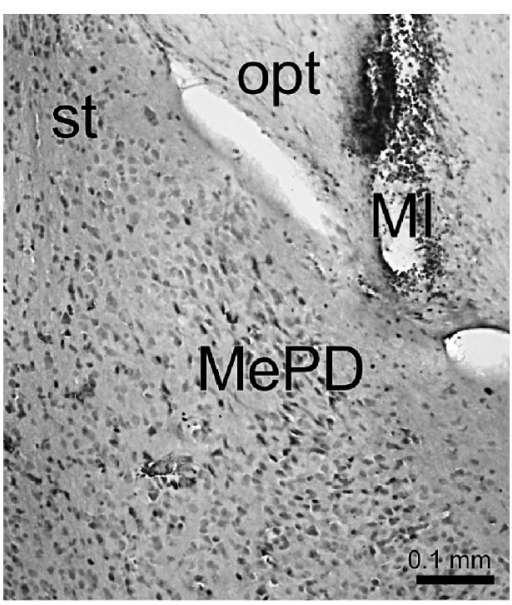

B
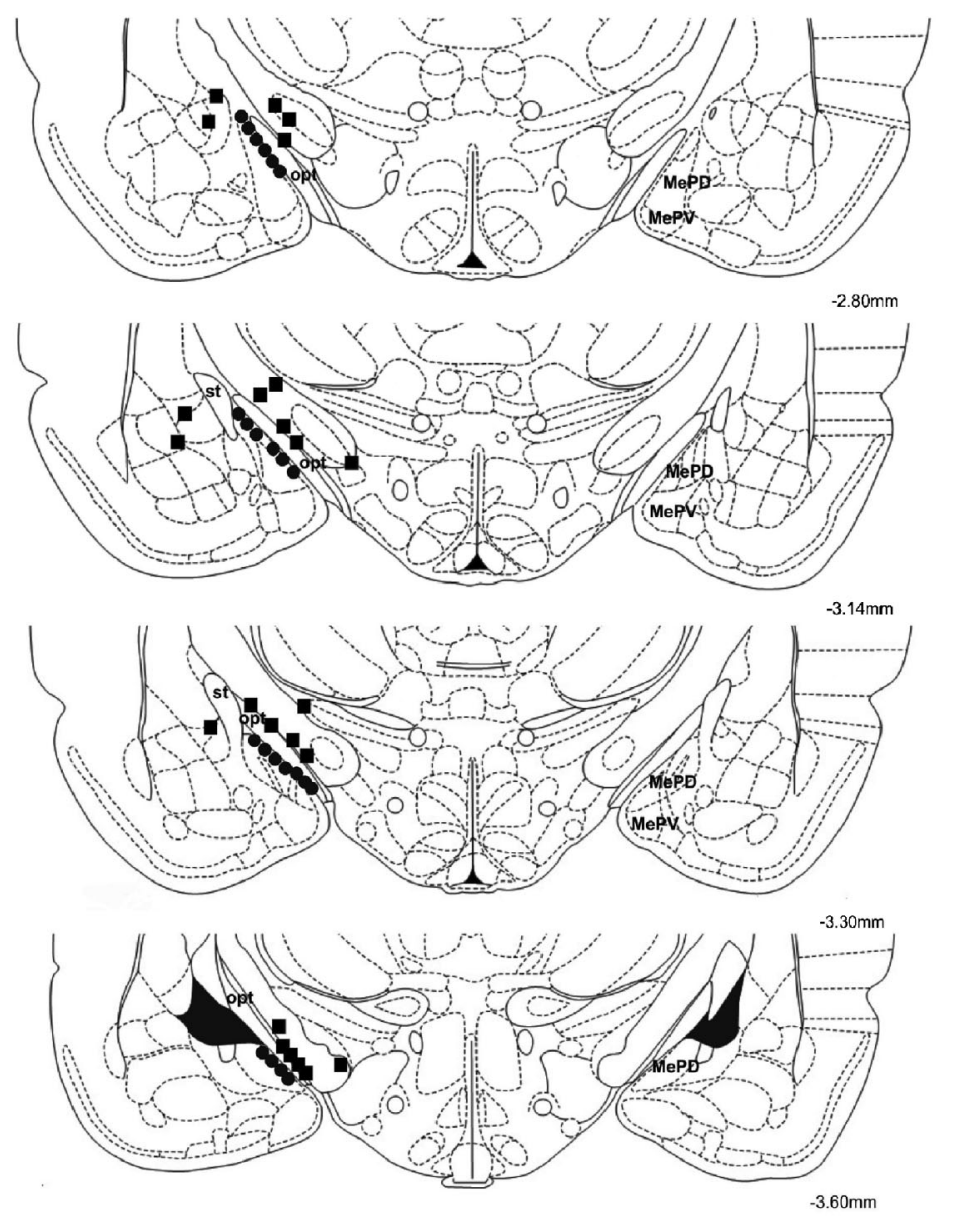

Figure 2. $A$, Photomicrograph of a coronal section of the ventral forebrain to show the microinjection (MI) site where substances were microinjected, diffused out and reached the posterodorsal medial amygdala (MePD), without lesioning it directly. In this case, the MePD was found approximately $3.30 \mathrm{~mm}$ below the bregma, lateral to the optic tract (opt) and ventral to the stria terminalis (st). Hematoxylin and eosin stain. $B$, Schematic drawing of coronal sections of the ventral part of the rat brain showing the MePD and the approximate sites for the microinjections of saline, oxytocin, somatostatin and angiotensin II (filled circles). Non-target sites are indicated by filled squares. All microinjections were administered to the right MePD and the points represent the approximate locale for drug spread. There are fewer points than the number of animals studied due to overlapping in the microinjection sites in different rats. No evident signs of parenchymal lesions in the MePD were found in the experimental groups. Coordinates are in millimeters posterior to the bregma (from 2.8 to $3.8 \mathrm{~mm}$ ). MePV, posteroventral part of the medial amygdaloid nucleus. Adapted from Ref. 30.
$3.6 \mathrm{~mm}$ lateral to the sagittal suture, and $5.7 \mathrm{~mm}$ below the dura mater (adapted from Ref. 30; Figure 2). After that, each rat received ketoprofen $(3 \mathrm{mg} / \mathrm{kg}$ in $0.3 \mathrm{~mL}$, ip), one injection per day for 2 days.

After 5 days, animals were anesthetized as cited earlier and had a polyethylene catheter [PE-10 soldered to a PE-50,
$0.28 \mathrm{~mm}$ inner diameter (ID), Biocorp, Australia, filled with sterile $0.9 \% \mathrm{NaCl}(\mathrm{pH} 7.4)$ and heparin] placed into the abdominal aorta and another into the inferior vena cava through the left femoral artery and vein, respectively. Each catheter was tunneled subcutaneously and exteriorized at the back of the rat neck. Gentamicin $(2 \mathrm{mg} / \mathrm{rat}$, im) was 
injected at the end of this procedure. The next day, the arterial catheter was attached to a $40-\mathrm{cm}$ polyethylene tube (PE-50, $0.5 \mathrm{~mm}$ ID, Biocorp), and a strain-gauge pressure transducer (P23 Db, Gould Statham, USA) was used for direct hemodynamic measurements. Signals passed through a preamplifier (Hewlett-Packard 8805, Puerto Rico) and were delivered to a microcomputer equipped with an analog-to-digital converter board (CODAS, $1 \mathrm{kHz}$, Dataq Instruments, USA). The recorded data were analyzed on a beat-to-beat basis.

All rats of the control and experimental groups were subjected to the same recording protocol. That is, after the catheter was connected to the transducer, rats were allowed to acclimate to a Plexiglas recording box $(25 \times 15 \times 10 \mathrm{~cm})$ over 20 to $30 \mathrm{~min}$ while cardiovascular parameters were being continuously monitored. Values of HR and AP were obtained during the last $15 \mathrm{~min}$ of this period to provide basal within group and between groups data to be compared with the effects of microinjections into the MePD. All recordings occurred during the morning (from 8:00 am to $12: 00$ noon) to avoid unpredictable circadian variations in the results.

Immediately after these initial recordings, a microinjection needle $(0.3 \mathrm{~mm}$ OD) was introduced into and $2 \mathrm{~mm}$ below the intracerebral guide cannula. Animals were then randomly assigned to 1 of 4 experimental groups that were manually microinjected with 1 ) vehicle (saline, $0.3 \mu \mathrm{L}$, $\mathrm{n}=7$ ) as the control group; 2) OT (10 ng/0.3 $\mu \mathrm{L}$ and $25 \mathrm{pg} /$ $0.3 \mu \mathrm{L}, \mathrm{n}=6$ in both groups); 3) SST ( $1 \mu \mathrm{M} / 0.3 \mu \mathrm{L}, \mathrm{n}=8$; and $0.05 \mu \mathrm{M} / 0.3 \mu \mathrm{L}, \mathrm{n}=5)$; 4) Ang II (50 pmol/0.3 $\mu \mathrm{L}$ and $50 \mathrm{fmol} / 0.3 \mu \mathrm{L}, \mathrm{n}=7$ in both groups). All drugs were purchased from Sigma Chemical Co. (USA). These higher and lower values of OT, SST, and Ang II proved to be effective in inducing central effects when microinjected into different brain areas (described in Ref. 6 and references therein). The microinjection procedure was monitored by the displacement of liquid and an air bubble inside the catheter connected to a $2-\mu \mathrm{L}$ Hamilton microsyringe (USA), lasted for $1 \mathrm{~min}$, and the needle remained inside the cannula for an additional minute to avoid reflux. After $4 \mathrm{~min}$, new cardiovascular recordings were obtained and lasted for the next 15 min. Additional MePD microinjections were completed before testing baroreceptor- and chemoreceptor-mediated reflexes. Then, every rat received 3 microinjections of each substance assigned to its experimental group as follows: one to test the MePD microinjection effects on the HR and $A P$ values, one before testing the baroreflex responses, and one before testing the chemoreflex responses. The order for testing baroreflex or chemoreflex activities was randomly chosen for each rat in all experimental groups. Obvious drug carryover effects were avoided, and new recordings were only started when hemodynamic values returned to baseline levels and remained stable during the recording time $(7,8)$.

\section{Baroreflex and chemoreflex stimulation}

Reflex responses were tested 5 min following each
MePD microinjection. Baroreflex-mediated changes were measured during peak increases or decreases in mean arterial pressure (MAP) after vena cava injection of a single dose of phenylephrine ( $8 \mu \mathrm{g} / 0.1 \mathrm{~mL}$, Sigma Chemical Co.), or sodium nitroprusside $(100 \mu \mathrm{g} / 0.1 \mathrm{~mL}$, Sigma Chemical Co.) dissolved in saline (8). These injections were made manually and, in all experimental groups, at similar and appropriate infusion rates, to lead to changes in MAP in the range $10-30 \mathrm{mmHg}$ with no evident artifactual activations. Various data points served to compose sigmoidal curves. All changes in MAP and HR were measured, and baroreflex sensitivity was determined by fitting the MAP and HR changes to a sigmoidal logistic equation, as follows: $H R=P_{1}+P_{2} /\left[1+\exp P_{3} \times\left(M A P-P_{4}\right)\right]$ where $P_{1}$ is the lower $\mathrm{HR}$ plateau [in beats per minute (bpm)], $\mathrm{P}_{2}$ is $\mathrm{HR}$ range between upper and lower curve plateaus (delta HR, in bpm), $P_{3}$ is a curvature coefficient that is independent of range, and $\mathrm{P}_{4}$ is MAP at one-half of the HR range (MAP ${ }_{50}$, in $\mathrm{mmHg}$ ), which is also the point for the calculation of the maximum gain. The upper plateau was calculated by the sum of $P_{1}$ and $P_{2}(7,8$, and references therein).

Chemoreflex sensitivity was tested under the same methodological conditions, but after the administration of increasing intravenous doses of potassium cyanide (KCN; $60,100,140$, and $180 \mu \mathrm{g} / \mathrm{kg}$; Merck, Germany). Injected volumes ranged from 0.06 to $0.18 \mathrm{~mL}$. Mean $\mathrm{HR}$ and MAP were measured continuously $10 \mathrm{~s}$ before and $15 \mathrm{~s}$ after each injection of these KCN doses. The inter-injection interval for each dose of $\mathrm{KCN}$ was around $4 \mathrm{~min}$, and a new dose was administered only when appropriate HR and MAP baselines had been reestablished $(7,8)$.

\section{Power spectral analysis and symbolic analysis}

These analyses demonstrate the different components in the variability of the $\mathrm{HR}$ and AP recordings and were applied to the results of the experimental groups as long as technically possible. For this reason, some results from the Ang II groups were not sufficient for further analyses and are shown only when they could be reliably done.

These methodological descriptions were reported previously ( 7,8 and references therein). Briefly, power spectral analysis was applied to pulse interval $(\mathrm{PI})$ and systolic arterial pressure (SAP) series. Tachograms and systograms were created from AP signals through the beat-to-beat $\mathrm{PI}$ and SAP, respectively. Frequency domain analysis of HRV (PI variability) and AP variability (APV) were obtained with an autoregressive algorithm on stationary sequences of 200 beats that were randomly chosen, but without artifacts, using the stationary test based on very low quantification of oscillations. Spectral estimation by the autoregressive model, using the residual theorem, provides central frequency and associated power with the additional advantage that, even with short segments of data, they can provide a reliable spectral resolution. HRV and APV correspond to the total power spectrum of $\mathrm{PI}$ and SAP. 
The low-frequency (LF; $0.2-0.75 \mathrm{~Hz}$ ) and high-frequency (HF; $0.75-3.0 \mathrm{~Hz}$ ) spectral components of $\mathrm{PI}$ and SAP were expressed in both absolute $\left(\mathrm{ms}^{2}\right.$ and $\mathrm{mmHg}^{2}$, respectively) and normalized units (NU). NU were obtained by calculating the power of LF and HF and correlating them to the total power without the very low frequency component (frequencies that were $<0.2 \mathrm{~Hz}$ ). This method estimates the center frequency and power of each relevant oscillatory component and indicates the involvement of the central control of the sympathetic/parasympathetic systems in the cardiovascular responses. The ratio between LF and HF components (LF/HF) was considered a synthetic expression of the sympathovagal balance. The coherence between the PI and the SAP variability was assessed by means of a cross-spectral analysis. The alpha index was obtained from the square root of the ratio between the $R-R$ interval and the SAP variability within the LF ranges and was calculated only when the magnitude of the squared coherence exceeded 0.5 (range $=0$ to 1 ) in the LF band. Using this alpha index for the LF component, beat-to-beat values of the PI and the SAP were used to estimate spontaneous baroreflex sensitivity.

Symbolic analysis was applied on the same sequences of PI and SAP data. This method consisted of the scattering of the time series over 6 bins, each identified by a number (symbol) from 0 to 5 . Symbolic series is a sequence of symbols for each bin, converted into patterns of 3 symbols. All 3 possible beat patterns are divided into 4 groups as follows: 1) no variations (OV, i.e., three identical symbols), 2) one variation (1V, two identical symbols and 1 different), 3) two like variations (2LV), and 4) two unlike variations (2UV). The OV is a marker of sympathetic modulation, a $1 \mathrm{~V}$ pattern reflects sympathetic and parasympathetic modulations, a 2LV pattern indicates sympathetic and parasympathetic modulations with vagal predominace, and $2 \mathrm{UV}$ is an exclusive marker of vagal modulation (see Ref. 31 and references therein).

\section{Histological procedure}

At the end of the experiments, rats were deeply anesthetized as described earlier and transcardially perfused with saline and $10 \%$ formalin solution. Brains were cut into $60-\mu \mathrm{m}$ thick sections using a vibratome (Leica, Germany) and stained with hematoxylin and eosin. The microinjection site was histologically determined and compared to the images of an atlas (30). This microinjection procedure was validated for accurate drug administration in small brain regions (32) - further comments about the effects of microinjected substances in the MePD can be found elsewhere $(7,8)$. Only those rats that had the microinjections directed to the MePD were considered for further analysis. Data from rats that had intraparenchimatous hemorrhage, mechanical lesions in the MePD, or microinjections that damaged the stria terminalis were not included.

Approximate sites for drug spread in the targeted area are shown in Figure 2A and B. As described previously (8), an inherent technical limitation of the present methodological approach is that drugs may have affected all parts of local neurons and glial cells, including both cell bodies and their prolongments. The specific diffusion rate for each of the substances microinjected into the MePD was not directly evaluated, and the average radius of drug diffusion was not estimated by virtue of comparing a dye with distinct physicochemical properties with the microinjected drugs. However, it is assumed that substances can diffuse an average radius of $0.5 \mathrm{~mm}$ from the point of microinjection (32). Here, it is also likely that the position of the guide cannula for the microinjection let the substances spread from the medial border of the MePD through its neuropil, and the coarse axons of the optic tract, situated in the back of the microinjection site, might have limited drug diffusion outside the MePD.

Nevertheless, non-target groups were also included to control for drug effects outside the intended area $(n=7$ rats for each microinjected substance). Cannulae and microinjections reached the vicinity of the MePD in these nontarget groups, and their data served to evaluate possible effects of the tested drugs in other medial amygdala subnuclei, other adjacent amygdaloid nuclei, in the optic tract, or in the ventral basal ganglia, all structures close to the MePD (Figure 2).

\section{Statistical analysis}

The basic requirements for the use of parametric analysis were assessed by the Kolmogorov-Smirnov and Levene tests. After that, the values of HR, SAP, diastolic AP (DAP), and MAP at basal conditions and the results of $\mathrm{HR}$ and AP evoked by the chemoreceptor reflex response were submitted to two-way analysis of variance (ANOVA) for repeated measures. Data obtained after the stimulation of the baroreflex were analyzed using one-way ANOVA. The Newman-Keuls post hoc test was used for multiple comparisons.

The normal distribution of data from spectral and symbolic analyses was determined by the Bonferroni test. After that, the results were analyzed using one-way ANOVA followed by the Tukey test. When Gaussian normality failed, a Kruskal-Wallis test on ranks and the Dunn's test were performed. In all cases, the statistically significant level was set a priori as $\mathrm{P} \leq 0.05$.

\section{Results}

Present results focus on the MePD results. To be concise, the non-target control data did not reproduce in any way the effects obtained in the experimental groups microinjected with the different neuropeptides in the MePD (ANOVA, $\mathrm{P}>0.05$ in all cases; data not shown).

\section{Hemodynamic status}

Basal hemodynamic values were within normal ranges for adult male rats recorded under laboratory conditions. 
Table 1. Basal hemodynamic data obtained before (control data) and after (test data) microinjections into the rat posterodorsal medial amygdala of saline $(0.3 \mu \mathrm{L}, \mathrm{n}=7)$, oxytocin (OT; $10 \mathrm{ng} / 0.3 \mu \mathrm{L}$ and $25 \mathrm{pg} / 0.3 \mu \mathrm{L}, \mathrm{n}=6$ in both groups), somatostatin (SST; $1 \mu \mathrm{M} /$ $0.3 \mu \mathrm{L}, \mathrm{n}=8$ and $0.05 \mu \mathrm{M} / 0.3 \mu \mathrm{L}, \mathrm{n}=5$ ), or angiotensin II (Ang II; $50 \mathrm{pmol} / 0.3 \mu \mathrm{L}$ and $50 \mathrm{fmol} / 0.3 \mu \mathrm{L} ; \mathrm{n}=7$ in both groups).

\begin{tabular}{|c|c|c|c|c|c|c|c|c|}
\hline \multirow[t]{2}{*}{ Groups } & \multicolumn{2}{|c|}{$\mathrm{SAP}(\mathrm{mmHg})$} & \multicolumn{2}{|c|}{$\mathrm{DAP}(\mathrm{mmHg})$} & \multicolumn{2}{|c|}{ MAP $(\mathrm{mmHg})$} & \multicolumn{2}{|c|}{$\mathrm{HR}(\mathrm{bpm})$} \\
\hline & Control & After & Control & After & Control & After & Control & After \\
\hline Saline & $136 \pm 9.0$ & $131.0 \pm 12.7$ & $90.1 \pm 4.6$ & $89.5 \pm 9.3$ & $111.6 \pm 5.6$ & $109.0 \pm 10.1$ & $360.2 \pm 29.3$ & $350.7 \pm 31.9$ \\
\hline От (10 ng) & $132.6 \pm 11.2$ & $135.7 \pm 7.8$ & $88.4 \pm 4.9$ & $88.5 \pm 2.2$ & $109.9 \pm 4.9$ & $111.4 \pm 3.5$ & $361.5 \pm 25.8$ & $375.7 \pm 26.2$ \\
\hline От (25 pg) & $131.7 \pm 5.2$ & $128.7 \pm 6.6$ & $93.7 \pm 7.9$ & $91.9 \pm 9.4$ & $111.9 \pm 6.5$ & $109.4 \pm 8.8$ & $370.7 \pm 23.4$ & $347.7 \pm 12.5$ \\
\hline SST $(1 \mu \mathrm{M})$ & $131.9 \pm 4.0$ & $135.4 \pm 7.0$ & $88.5 \pm 3.8$ & $91.6 \pm 6.3$ & $109.7 \pm 3.3$ & $112.7 \pm 6.9$ & $352.5 \pm 39.6$ & $365.9 \pm 38.1$ \\
\hline SST $(0.05 \mu \mathrm{M})$ & $131.5 \pm 7.7$ & $124.0 \pm 6.8$ & $94.1 \pm 6.4$ & $89.4 \pm 5.9$ & $111.4 \pm 5.5$ & $106.6 \pm 6.3$ & $351.8 \pm 21.0$ & $340.0 \pm 25.4$ \\
\hline Ang II (50 fmol) & $134.0 \pm 6.0$ & $131.1 \pm 8.5$ & $94.8 \pm 6.1$ & $95.4 \pm 10.4$ & $113.5 \pm 5.5$ & $112.5 \pm 9.5$ & $354.7 \pm 37.5$ & $353.6 \pm 53.3$ \\
\hline Ang II (50 pmol) & $134.4 \pm 11.8$ & $134.7 \pm 9.2$ & $94.0 \pm 5.5$ & $94.2 \pm 5.3$ & $113.5 \pm 7.6$ & $113.5 \pm 6.7$ & $354.0 \pm 42.2$ & $354.9 \pm 39.1$ \\
\hline
\end{tabular}

Data are reported as means \pm SD. SAP: systolic arterial pressure; DAP: diastolic arterial pressure; MAP: mean arterial blood pressure; HR: heart rate. No statistically significant differences were found comparing data between experimental groups (one-way ANOVA).

No relevant statistical difference was found in the HR, SAP, DAP, and MAP following microinjections of saline or OT, SST, and Ang II (ANOVA, P>0.05 in all cases). There were no lasting effects of the microinjections in any experimental group, which provided stable baseline recordings prior to the assessment of the baroreflex and the chemoreflex responses (Table 1).

\section{Effects of baroreflex activation}

Reflex control of the HR was analyzed by fitting sigmoidal curves to different data points of each animal. Mean values were calculated for each experimental group (Figure 3). The $M P_{50}$, which describes the MAP value at one-half of the HR

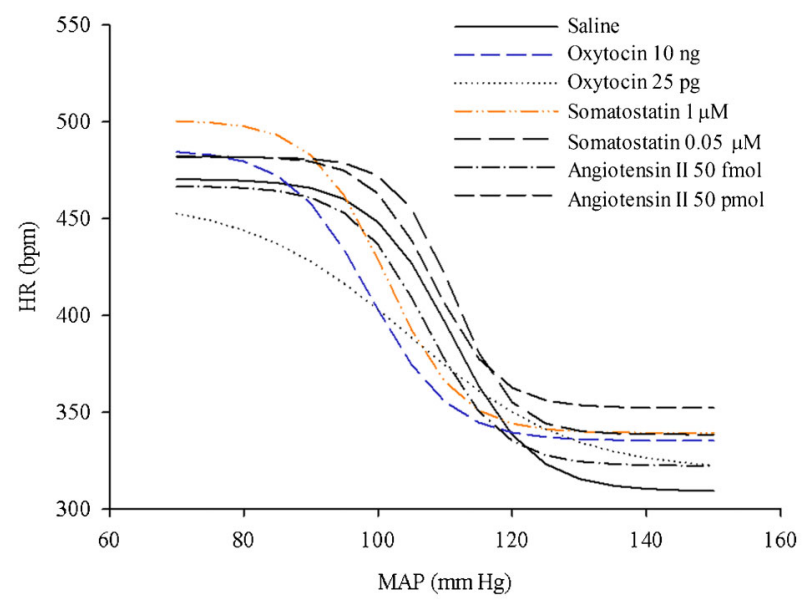

Figure 3. Plots showing the average values for the relationship between mean arterial blood pressure (MAP) and heart rate (HR), using logistic sigmoidal baroreceptor curve analysis, of rats that received the following microinjections in the posterodorsal medial amygdala: saline $(0.3 \mu \mathrm{L}, \mathrm{n}=7)$, oxytocin $(10 \mathrm{ng} / 0.3 \mu \mathrm{L}$ and $25 \mathrm{pg} /$ $0.3 \mu \mathrm{L}, \mathrm{n}=6$ in both groups), somatostatin $(1 \mu \mathrm{M} / 0.3 \mu \mathrm{L}, \mathrm{n}=8$ and $0.05 \mu \mathrm{M} / 0.3 \mu \mathrm{L}, \mathrm{n}=5)$, or angiotensin II (50 pmol/0.3 $\mu \mathrm{L}$ and $50 \mathrm{fmol} / 0.3 \mu \mathrm{L} ; \mathrm{n}=7$ in both groups). range in the baroreflex curve, following the injections of phenylephrine and sodium nitroprusside showed an overall statistical difference between groups $[F(6,47)=3.37$, $\mathrm{P}<0.01$ ]. The post hoc comparisons revealed that the MePD microinjection of OT (10 ng) or SST $(1 \mu \mathrm{M})$ promoted a significant decrease in the $\mathrm{MAP}_{50}$, shifting the barocurve to the left and to lower HR values when compared with the results from the saline microinjected group $(P<0.05$ in both cases).

An overall statistical difference was also found in the maximum gain of the reflex responses when the AP was increased by phenylephrine or decreased by sodium nitroprusside when compared between the experimental groups $[F(6,47)=2.56, P<0.03]$, but post hoc comparisons did not show differences between any tested substances compared with saline. For the $\operatorname{HR}$ range $[F(6,47)=1.29$, $P=0.27]$, the lower plateau $[F(6,47)=1.53, P=0.19]$ and the upper plateau $[F(6,47)=1.19, P=0.09]$ did not differ between the experimental groups.

\section{Effects of chemoreflex activation}

Data for chemoreflex activation are shown in Figure 4. There was a statistically significant difference in the HR after injection of the increasing doses of $\operatorname{KCN}[F(3,123)=69.77$, $\mathrm{P}=0.01]$ and between experimental groups microinjected into the MePD $[F(6,123)=2.82, P=0.02]$, but no statistical interaction was found between these two factors $[F(18,123)=1.51, P=0.09]$.

On the other hand, the values of MAP obtained after the injection of the different doses of $\mathrm{KCN}$ reached statistically significant levels $[F(3,123)=17.26, P=0.01]$ and, although data did not differ between the experimental groups $[F(6,123)=1.08, P=0.38]$, the interaction between these two factors was significantly different $[F(18,123)=2.22$, $\mathrm{P}<0.01]$. The post hoc test showed that, compared with saline, OT (10 ng) microinjected into the MePD led to a marked increase in the MAP following KCN $(180 \mu \mathrm{g} / \mathrm{kg}$; $\mathrm{P}<0.05)$. No other comparison showed a significant 


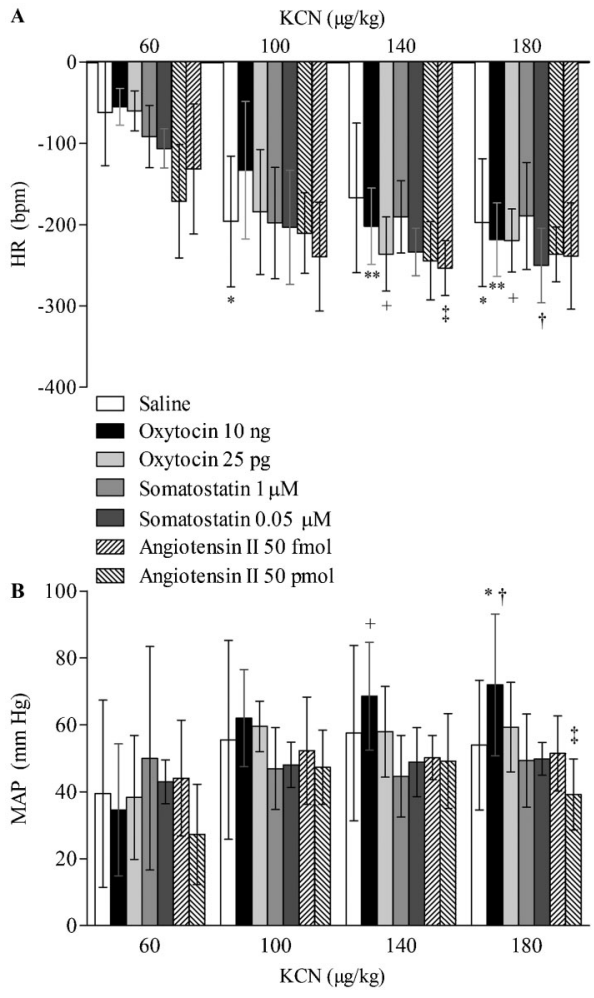

Figure 4. $A$, Heart rate $(\mathrm{HR})$ and $B$, mean arterial blood pressure (MAP) of the chemoreceptor reflex response induced by increasing doses of potassium cyanide (KCN, from 60 to $180 \mu \mathrm{g} / \mathrm{kg}$ ) in rats that received microinjections into the posterodorsal medial amygdala of saline $(0.3 \mu \mathrm{L}, \mathrm{n}=7)$, oxytocin (OT; $10 \mathrm{ng} / 0.3 \mu \mathrm{L}$ and $25 \mathrm{pg} / 0.3 \mu \mathrm{L}, \mathrm{n}=6$ in both groups), somatostatin (SST; $1 \mu \mathrm{M}$ / $0.3 \mu \mathrm{L}, \mathrm{n}=8$ and $0.05 \mu \mathrm{M} / 0.3 \mu \mathrm{L}, \mathrm{n}=5$ ), or angiotensin II (Ang II; $50 \mathrm{pmol} / 0.3 \mu \mathrm{L}$ and $50 \mathrm{fmol} / 0.3 \mu \mathrm{L} ; \mathrm{n}=7$ in both groups). Data are reported as means $\pm S D$. Data were submitted to the two-way ANOVA test for repeated measures and the Newman-Keuls post hoc test. In A, for HR: *P $<0.01$ compared with $60 \mu \mathrm{g} / \mathrm{kg} \mathrm{KCN}$ in the group microinjected with saline. ${ }^{* *} \mathrm{P}<0.01$ compared with $60 \mu \mathrm{g} / \mathrm{kg}$ $\mathrm{KCN}$ in the group microinjected with OT $10 \mathrm{ng} .{ }^{+} \mathrm{P}<0.01 \mathrm{com}-$ pared with $60 \mu \mathrm{g} / \mathrm{kg} \mathrm{KCN}$ in the group microinjected with OT $25 \mathrm{pg}$. ${ }^{\dagger} \mathrm{P}<0.01$ compared with $60 \mu \mathrm{g} / \mathrm{kg} \mathrm{KCN}$ in the group microinjected with SST $0.05 \mu \mathrm{M}$. ${ }^{\mathrm{P}}<0.05$ compared with $60 \mu \mathrm{g} /$ $\mathrm{kg} \mathrm{KCN}$ in the group microinjected with Ang II 50 pmol. In $B$, for MAP: ${ }^{*} \mathrm{P}<0.01$ compared with $60 \mu \mathrm{g} / \mathrm{kg} \mathrm{KCN}$ in the group microinjected with OT $10 \mathrm{ng} .{ }^{+} \mathrm{P}<0.05$ compared with $140 \mu \mathrm{g} / \mathrm{kg}$ $\mathrm{KCN}$ in the group microinjected with SST $1 \mu \mathrm{M}$. ${ }^{\dagger} \mathrm{P}<0.05$ compared with $180 \mu \mathrm{g} / \mathrm{kg} \mathrm{KCN}$ in the group microinjected with saline. ${ }^{\mathrm{P}}<0.05$ compared with $180 \mu \mathrm{g} / \mathrm{kg} \mathrm{KCN}$ in the group microinjected with OT $10 \mathrm{ng}$. Expanded and adapted from Ref. 6 with permission from Nova Science Publishers (USA).

statistical difference between the experimental groups and the saline group $(P>0.05)$.

\section{Power spectral analysis}

Power spectral analysis results are shown in Table 2 and Figure 5 . There were no statistically significant differences in the SAP $[F(5,33)=1.63 ; P=0.17]$, in the mean values of $H R$
$[F(5,33)=2.01 ; P=0.10]$, in the absolute LF component $[F(5,33)=1.87 ; P=0.125]$, or in the absolute HF component of the SAP between the experimental groups $[F(5,33)=$ $1.41 ; P=0.24]$

However, the HRV analysis showed a statistically significant difference between experimental groups $[F(5,33)$ $=4.50 ; \mathrm{P}<0.05]$. The post hoc comparison showed that OT (25 pg), SST ( 1 and $0.05 \mu \mathrm{M})$, and Ang II (50 pmol) led to increased values compared with saline $(\mathrm{P}<0.05$ in all cases). In addition, the LF component of the HRV, in NU, presented a statistically significant difference between the experimental groups $[F(5,33)=2.61 ; P<0.05]$ and the post hoc test indicated that SST $(1 \mu \mathrm{M}$ and $0.05 \mu \mathrm{M})$ promoted an increase in this parameter compared with saline $(P<0.05$ in both cases). There was also an overall difference in the absolute power of the HF component of the $\operatorname{HRV}[F(5,33)=2.65 ; \mathrm{P}<0.05]$, and the post hoc comparison showed that OT (10 ng) promoted an increase in this parameter compared with saline $(\mathrm{P}<0.05)$.

The sympathetic/parasympathetic balance obtained from the alpha index also showed a statistically significant difference between experimental groups $[F(5,33)=2,71$; $\mathrm{P}<0.05]$ and, specifically, SST $(0.05 \mu \mathrm{M})$ promoted higher values compared with saline (Newman-Keuls test, $P<0.05$ ).

\section{Symbolic analysis}

Results are presented in Table 3 and Figure 5. Compared with control data, the microinjections of OT (10 ng and $25 \mathrm{pg}$ ) and SST (1 and $0.05 \mu \mathrm{M})$ did not cause evident effects (Newman-Keuls test, $\mathrm{P}>0.05$ ), but there was a significant decrease in the 2UV pattern after Ang II (50 fmol) microinjection into the MePD when compared with saline $[F(5,34)=2.282, \mathrm{P}<0.05$; Newman-Keuls test, $\mathrm{P}<0.05]$.

\section{Discussion}

Our present results reinforce findings that the rat MePD is a component of the central network that modulates baroreceptor- and chemoreceptor-mediated cardiovascular adjustments. These data match with the evident presence of neuropeptides and their receptors in the MePD (18-22) and indicate functional implications that deserve further evaluation, as follows.

First, it is interesting that the tested neuropeptides promoted long-lasting effects (in the order of minutes) when microinjected into the MePD, as previously reported for classical neurotransmitters [glutamate, GABA, and histamine], which appears to be a particularity of this brain area $(7,8)$. In addition, the MePD contributes more to changes in cardiovascular reflexes than in basal HR and AP levels. As occurs for other amygdaloid nuclei (33), it is possible that transmitter-mediated excitatory, inhibitory, and/or disinhibitory mechanisms in the MePD can promote a flexible, dose- and context-dependent modulation of the central control of sympathetic/parasympathetic output (6). We also propose that the rat MePD is responsive to different 
Table 2. Cardiovascular parameters of power spectral analysis calculated from sampled data of rats that received microinjections into the posterodorsal medial amygdala of saline $(0.3 \mu \mathrm{L})$, oxytocin (OT; $10 \mathrm{ng} / 0.3 \mu \mathrm{L}$ and $25 \mathrm{pg} / 0.3 \mu \mathrm{L})$, somatostatin $(\mathrm{SST} ; 1 \mu \mathrm{M} / 0.3 \mu \mathrm{L}$ and $0.05 \mu \mathrm{M} / 0.3 \mu \mathrm{L}$ ), or angiotensin II (Ang II; $50 \mathrm{pmol} / 0.3 \mu \mathrm{L}$ ).

\begin{tabular}{|c|c|c|c|c|c|c|}
\hline Measurement & $\begin{array}{l}\text { Saline } \\
(n=7)\end{array}$ & $\begin{array}{l}\text { OT } 10 \mathrm{ng} \\
(\mathrm{n}=6)\end{array}$ & $\begin{array}{l}\text { OT } 25 \mathrm{pg} \\
\quad(\mathrm{n}=6)\end{array}$ & $\begin{array}{l}\text { SST } 1 \mu \mathrm{M} \\
\quad(\mathrm{n}=8)\end{array}$ & $\begin{array}{c}\text { SST } 0.05 \mu \mathrm{M} \\
\quad(\mathrm{n}=5)\end{array}$ & $\begin{array}{l}\text { Ang II } 50 \text { pmol } \\
\qquad(\mathrm{n}=7)\end{array}$ \\
\hline $\operatorname{HRV}\left(\mathrm{ms}^{2}\right)$ & $13.35 \pm 4.18$ & $29.34 \pm 9.57$ & $46.75 \pm 18.7^{*}$ & $49.80 \pm 16.90^{*}$ & $58.81 \pm 39.59^{*}$ & $50.78 \pm 22.23^{*}$ \\
\hline $\mathrm{f}_{\mathrm{LF}}(\mathrm{Hz})$ & $0.54 \pm 0.10$ & $0.50 \pm 0.10$ & $0.51 \pm 0.12$ & $0.45 \pm 0.10$ & $0.42 \pm 0.07$ & $0.56 \pm 0.10$ \\
\hline $\operatorname{LF}\left(\mathrm{ms}^{2}\right)$ & $0.49 \pm 0.26$ & $1.51 \pm 0.89$ & $6.48 \pm 6.21^{*}$ & $3.04 \pm 2.62$ & $5.70 \pm 4.88$ & $3.80 \pm 3.59$ \\
\hline LF (NU) & $9.24 \pm 3.55$ & $13.45 \pm 6.41$ & $15.53 \pm 6.63$ & $19.66 \pm 8.17^{*}$ & $22.38 \pm 11.86^{*}$ & $14.46 \pm 7.66$ \\
\hline $\mathrm{f}_{\mathrm{HF}}(\mathrm{Hz})$ & $1.84 \pm 1.37$ & $1.87 \pm 10.95^{*}$ & $1.76 \pm 151$ & $1.70 \pm 1.68$ & $1.67 \pm 1.21$ & $1.65 \pm 1.29$ \\
\hline $\mathrm{HF}\left(\mathrm{ms}^{2}\right)$ & $4.68 \pm 2.01$ & $11.59 \pm 10.64^{*}$ & $30.16 \pm 25.36$ & $12.22 \pm 5.81$ & $17.02 \pm 5.69$ & $24.98 \pm 22.46$ \\
\hline $\mathrm{HF}(\mathrm{NU})$ & $87.38 \pm 5.12$ & $80.76 \pm 12.09$ & $84.39 \pm 6.67$ & $80.31 \pm 8.16$ & $77.62 \pm 11.86$ & $84.11 \pm 8.02$ \\
\hline LF/HF & $0.11 \pm 0.04$ & $0.18 \pm 0.11$ & $0.19 \pm 0.09$ & $0.26 \pm 0.13$ & $0.32 \pm 0.25$ & $0.18 \pm 0.11$ \\
\hline APV $\left(\mathrm{mmHg}^{2}\right)$ & $8.84 \pm 3.48$ & $20.16 \pm 10.70$ & $10.54 \pm 5.89$ & $15.80 \pm 8.82$ & $12.32 \pm 5.98$ & $17.46 \pm 12.55$ \\
\hline $\operatorname{VLF}\left(\mathrm{mmHg}^{2}\right)$ & $5.78 \pm 4.09$ & $11.07 \pm 8.76$ & $3.62 \pm 2.84$ & $8.90 \pm 9.22$ & $8.71 \pm 7.13$ & $10.13 \pm 12.49$ \\
\hline $\mathrm{LF}\left(\mathrm{mmHg}^{2}\right)$ & $1.72 \pm 0.77$ & $5.78 \pm 3.31$ & $4.04 \pm 3.18$ & $4.20 \pm 3.16$ & $2.73 \pm 1.79$ & $3.60 \pm 1.93$ \\
\hline $\mathrm{HF}\left(\mathrm{mmHg}^{2}\right)$ & $1.33 \pm 0.43$ & $3.24 \pm 2.38$ & $2.86 \pm 3.26$ & $2.70 \pm 1.02$ & $0.88 \pm 0.36$ & $2.29 \pm 2.06$ \\
\hline Alpha index $(\mathrm{ms} / \mathrm{mmHg})$ & $0.53 \pm 0.11$ & $0.53 \pm 0.14$ & $1.16 \pm 0.52$ & $1.09 \pm 0.79$ & $1.56 \pm 0.65^{*}$ & $1.29 \pm 0.93$ \\
\hline
\end{tabular}

Data are reported as means $\pm S D$. $H R V$ : heart rate variability; $f_{\mathrm{LF}}$ : central low frequency; $\mathrm{f}_{\mathrm{HF}}$ : central high frequency; $L F$ : low frequency power; HF: high frequency power; APV: arterial pressure variability; VLF: very low frequency power. ${ }^{*} \mathrm{P}<0.05$, compared to saline (one-way ANOVA and the Tukey post hoc test or the Kruskal-Wallis test and the Dunn's post hoc test).

neurotransmitters and neuropeptides that code distinct synaptic inputs for specific fine-tunings of centrally mediated cardiovascular reflexes and the dynamic display of behaviors in awake animals $(7,8)$. It is now desirable to determine how neurotransmitters and neuropeptides in the MePD can modulate the activity of specific output pathways that reach other brain areas related to central cardiovascular control.

Second, all the neuropeptides tested here evoked a higher HRV as revealed by the power spectral analysis. The predominant central sympathetic or parasympathetic modulation of the cardiovascular system involves the balance between the spectral components in favor of the LF or the HF band, respectively (34). However, it is noteworthy that OT microinjections into the MePD did not cause specific effects on the parameters evaluated by the symbolic analysis. Then, it is possible that higher absolute LF and HF power values (after OT $25 \mathrm{pg}$ and $10 \mathrm{ng}$, respectively) can be explained by the increase in HRV itself and the change of the HF peak value, which is also associated with ventilatory components and might be correlated with an increased respiratory rate following OT (10 ng) microinjection into the MePD. The participation of rat MePD in the central control of breathing is currently unknown. This is a working hypothesis that needs to be confirmed with other methodological approaches and opens a new and interesting line of research.

Indeed, OT can have site-specific roles on the central modulation of cardiovascular responses instead of similar and widespread actions. For example, although intracerebroventricular injection of OT did not evoke significant cardiovascular effects (35), unilateral microinjections of an
OT receptor antagonist in the NTS reduced the long-lasting vasopressor and tachycardic responses elicited by local microinjection of this neuropeptide (24). OT also counteracted the vasodepressor and bradycardic responses induced by glutamate in this nucleus (24). Data from the $\mathrm{CeA}$, a component of the extended amygdala, provided another interpretation for the effects of OT (36). That is, OT microinjected into the $\mathrm{CeA}$ promoted an elevation in plasma corticosterone, but not epinephrine and norepinephrine. At the same time, the induction of a tachycardic response was attributable to a somatic-sympathetic/parasympathetic coupling rather than to a genuine "autonomic" activation (36). Here, the microinjection of OT into the MePD also appeared to affect central cardiovascular control only indirectly.

Otherwise, microinjection of SST into the MePD caused an increase in the HRV suggestive of a central sympathetic and parasympathetic coactivation. Because this finding was also accompanied by an increase in the LF (in NU), they rather point to changes in the central sympathetic regulation. This increase in the HRV was also accompanied by a higher alpha index, which indicates the relationship between the LF components of the HRV and the APV along with an increase in baroreflex sensitivity. The precise mechanism by which SST exerts its effects in the MePD still remains to be established. SST inhibits the presynaptic release of glutamate, activates potassium channels, and inhibits voltagegated calcium channels via sst2 or sst5 receptors (37 and references therein). SST can also promote an inhibitory action by acting directly on its receptors or indirectly via GABAergic synapses in the MeA (21). From our present results, SST induced a central sympathetic effect, whereas, comparatively, GABA in the MePD decreased the upper 

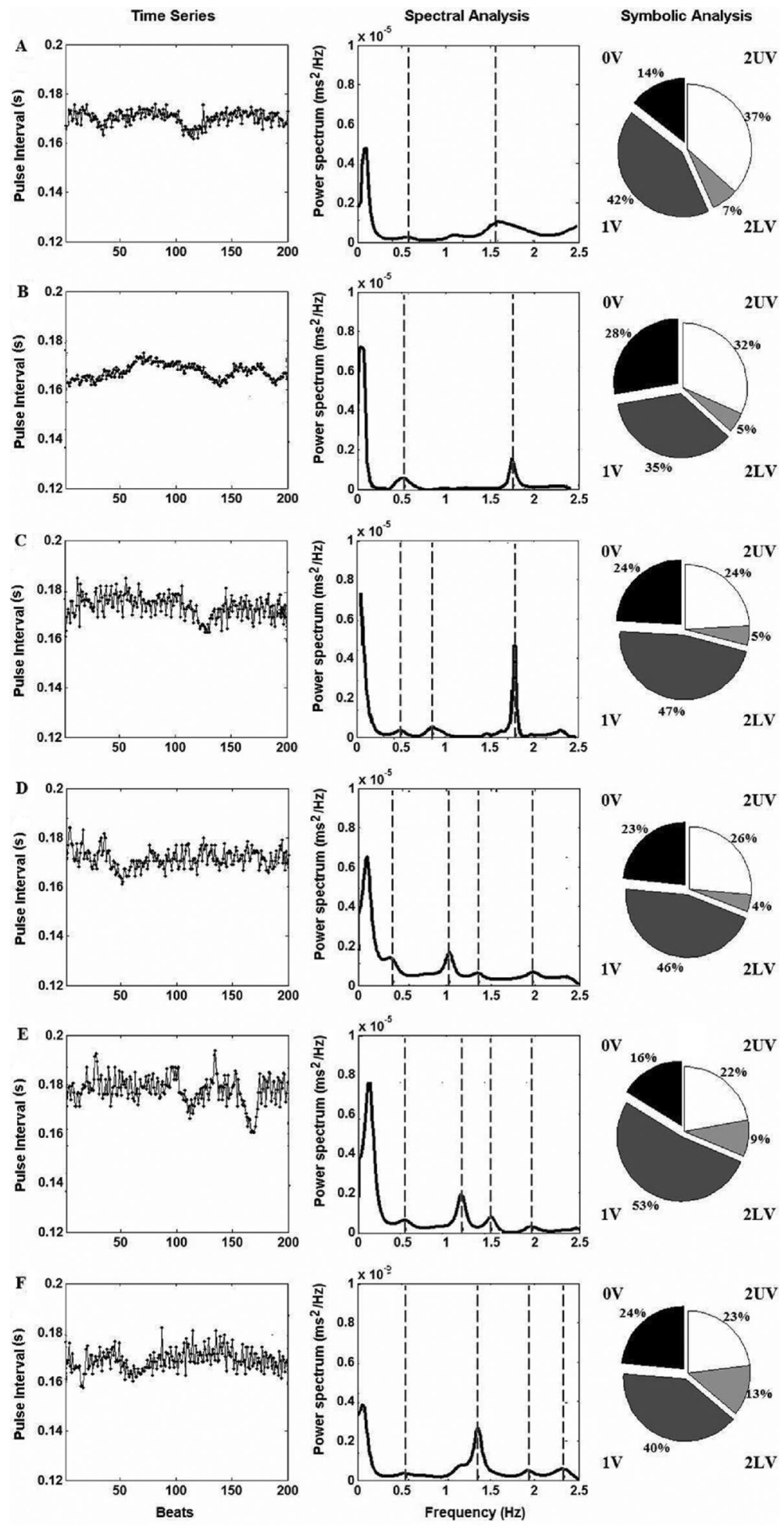

plateau of the baroreflex curve and induced higher values of HRV linked with the central parasympathetic control of the cardiovascular system (8). Therefore, these findings demonstrate non-overlapping effects of SST and GABA on

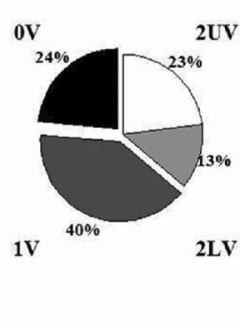

Figure 5. Power spectrum and symbolic analysis applied to a time series of cardiovascular parameters of rats. The columns show the pulse interval series, power spectrum and the symbolic pattern distribution for the data obtained from the experimental groups that received microinjections into the posterodorsal medial amygdala with $A$, saline $(0.3 \mu \mathrm{L}, \mathrm{n}=7), B$, oxytocin $10 \mathrm{ng}$ and $C$, $25 \mathrm{pg}$ ( $\mathrm{n}=6$ in both groups), $D$, somatostatin $1 \mu \mathrm{M}$ $(\mathrm{n}=8)$ and $E, 0.05 \mu \mathrm{M}(\mathrm{n}=5)$, or $F$, angiotensin II $50 \mathrm{pmol}$ (for the power spectral analysis) and $50 \mathrm{fmol}$ (for the symbolic analysis; $\mathrm{n}=7$ in both groups). Values are from representative samples of each experimental group. Mean values for all studied animals are shown in Tables 2 and 3.

cardiovascular responses when acting in the rat MePD.

Finally, microinjection of Ang II into the MePD increased the HRV, did not affect power spectral components, but reduced the $2 \mathrm{UV}$ pattern of the symbolic analysis, which 
Table 3. Cardiovascular parameters of symbolic analysis calculated from sampled data of rats that received microinjections into the posterodorsal medial amygdala of saline $(0.3 \mu \mathrm{L})$, oxytocin $(\mathrm{OT} ; 10 \mathrm{ng} / 0.3 \mu \mathrm{L}$ and $25 \mathrm{pg} / 0.3 \mu \mathrm{L})$, somatostatin $(\mathrm{SST} ; 1 \mu \mathrm{M} / 0.3 \mu \mathrm{L}$ and $0.05 \mu \mathrm{M} / 0.3 \mu \mathrm{L}$ ), or angiotensin II (Ang II; $50 \mathrm{fmol} / 0.3 \mu \mathrm{l})$.

\begin{tabular}{lccccrc}
\hline Measurement & $\begin{array}{c}\text { Saline } \\
(\mathrm{n}=7)\end{array}$ & $\begin{array}{c}\text { OT 10 } \mathrm{ng} \\
(\mathrm{n}=6)\end{array}$ & $\begin{array}{c}\text { OT 25 pg } \\
(\mathrm{n}=6)\end{array}$ & $\begin{array}{c}\text { SST 1 } \mu \mathrm{M} \\
(\mathrm{n}=8)\end{array}$ & $\begin{array}{c}\text { SST 0.05 } \mu \mathrm{M} \\
(\mathrm{n}=5)\end{array}$ & $\begin{array}{c}\text { Ang II 50 fmol } \\
(\mathrm{n}=7)\end{array}$ \\
\hline OV\% pattern & $15.71 \pm 5.28$ & $24.06 \pm 12.49$ & $25.42 \pm 19.05$ & $24.29 \pm 8.91$ & $21.30 \pm 4.85$ & $22.19 \pm 8.16$ \\
1V\% pattern & $44.39 \pm 3.78$ & $38.86 \pm 6.74$ & $41.71 \pm 5.05$ & $44.60 \pm 5.84$ & $45.95 \pm 4.39$ & $43.04 \pm 4.50$ \\
2LV\% pattern & $7.92 \pm 4.45$ & $4.96 \pm 3.47$ & $6.67 \pm 7.97$ & $5.13 \pm 2.49$ & $7.24 \pm 3.26$ & $11.23 \pm 4.45$ \\
2UV\% pattern & $36.85 \pm 6.94$ & $32.12 \pm 9.71$ & $26.21 \pm 10.64$ & $26.00 \pm 10.52$ & $25.51 \pm 5.33$ & $24.96 \pm 6.50^{*}$ \\
\hline
\end{tabular}

Data are reported as means \pm SD. $0 \mathrm{~V}: 3$ identical symbols; $1 \mathrm{~V}$ : one variation (2 identical symbols and 1 different symbol); $2 \mathrm{LV}$ : two like variations; $2 U V$ : two unlike variations. ${ }^{*} \mathrm{P}<0.05$, compared to saline (one-way ANOVA and the Newman-Keuls post hoc test).

was linked to cardiac vagal activity in pharmacological tests (38). In the group microinjected with 50 pmol ANG II, it is also possible that the lower bradycardic response produced by pressure increase was related to the blunting of the parasympathetic component, and the higher baroreflex gain observed could be associated with the higher tachycardic response after AP reduction. Microinjection, electrophysiological, and lesion studies demonstrate complex interactions and multiple sites for the action of Ang II on cardiovascular control and in different brain areas (26-29). It is interesting that AT1A receptors are involved in neuronal activation and cardiovascular change after an olfactory-mediated psychosocial stress in mice (39). Acting in the MeA, Ang II might inhibit stress-induced aversive responses (39). However, no strain difference (between spontaneously hypertensive and normotensive Wistar male rats) was identified in c-Fos immunoreactivity in the MeA after aversive air jet or air noise stress stimulation (40). Then, it is possible that different species and/or types and intensity of sensory stimulation can trigger the Ang II-evoked responses. Marked central Ang II actions on the cardiovascular system, partly stimulating sympathetic responses (27), were not found after its microinjection into the MePD. Rather, we found a central parasympathetic effect and, in agreement with NTS data (29), Ang II in the MePD

\section{References}

1. de Olmos JS, Beltramino CA, Alheid G. Amygdala and extended amygdala of the rat: a cytoarchitectonical, fibroarchitectonical, and chemoarchitectonical survey. In: Paxinos G. (Editor), The rat nervous system. Amsterdam: Elsevier Academic Press; 2004. p 509-603.

2. Dayas CV, Buller KM, Day TA. Neuroendocrine responses to an emotional stressor: evidence for involvement of the medial but not the central amygdala. Eur J Neurosci 1999; 11: 23122322, doi: 10.1046/j.1460-9568.1999.00645.x.

3. Singewald N, Chicchi GG, Thurner CC, Tsao KL, Spetea M, Schmidhammer $\mathrm{H}$, et al. Modulation of basal and stressinduced amygdaloid substance $P$ release by the potent and selective NK1 receptor antagonist L-822429. J Neurochem 2008; 106: 2476-2488, doi: 10.1111/j.1471-4159.2008.05596.x. potentiated the chemoreflex-mediated decrease in HR frequency. These new findings add and expand the idea of site-specific effects of Ang II on central cardiovascular control and reinforce the multiple modulatory actions of the MePD.

In summary, our work provides additional data for MePD modulation of the baroreflex and chemoreflex cardiovascular responses in awake rats. Local microinjections promoted neuropeptidergic-selective responses and involved the central activation of the sympathetic and parasympathetic effector systems. This MePD plastic capacity could provide the animal with a dynamic mechanism of cardiovascular control suitable for the ongoing demands of social behaviors, for which the MePD is a relevant component in integrated brain circuits (2-6,9-11). Besides the adjustment of homeostatic responses, these neuropeptidergic actions in the MePD can also be involved in the pathophysiology of cardiovascular diseases, such as hypertension (14-16), a possibility that deserves further studies as well.

\section{Acknowledgments}

Research supported by CNPq/PDJ (\#501041/2012-5) and FAPERGS (\#1016957). P. Dal Lago and A.A. RasiaFilho are $\mathrm{CNPq}$ researchers.

4. Choi GB, Dong HW, Murphy AJ, Valenzuela DM, Yancopoulos GD, Swanson LW, et al. Lhx6 delineates a pathway mediating innate reproductive behaviors from the amygdala to the hypothalamus. Neuron 2005; 46: 647-660, doi: 10.1016/j.neuron.2005.04.011.

5. Rasia-Filho AA, Haas D, de Oliveira AP, de Castilhos J, Frey $\mathrm{R}$, Stein D, et al. Morphological and functional features of the sex steroid-responsive posterodorsal medial amygdala of adult rats. Mini Rev Med Chem 2012; 12: 1090-1106, doi: 10.2174/138955712802762211.

6. Quagliotto E, Casali KR, Dal Lago P, Rasia-Filho AA. Neurotransmitter and neuropeptidergic modulation of cardiovascular responses evoked by the posterodorsal medial amygdala of adult male rats. In: Yilmazer-Hanke D. (Editor), 
Insights into the amygdala. Hauppauge: Nova Science Publishers; 2012. p 139-165.

7. Quagliotto E, Neckel H, Riveiro DF, Casali KR, Mostarda C, Irigoyen $\mathrm{MC}$, et al. Histamine in the posterodorsal medial amygdala modulates cardiovascular reflex responses in awake rats. Neuroscience 2008; 157: 709-719, doi: 10.1016/ j.neuroscience.2008.09.053.

8. Neckel H, Quagliotto E, Casali KR, Montano N, Dal Lago P, Rasia-Filho AA. Glutamate and GABA in the medial amygdala induce selective central sympathetic/parasympathetic cardiovascular responses. Can J Physiol Pharmacol 2012; 90: 525-536, doi: 10.1139/y2012-024.

9. Chiou RJ, Kuo CC, Yen CT. Comparisons of terminal densities of cardiovascular function-related projections from the amygdala subnuclei. Auton Neurosci 2014; 181: 21-30, doi: 10.1016/j.autneu.2013.12.002.

10. Saha S. Role of the central nucleus of the amygdala in the control of blood pressure: descending pathways to medullary cardiovascular nuclei. Clin Exp Pharmacol Physiol 2005; 32: 450-456, doi: 10.1111/j.1440-1681.2005.04210.x.

11. Petrovich GD, Canteras NS, Swanson LW. Combinatorial amygdalar inputs to hippocampal domains and hypothalamic behavior systems. Brain Res Rev 2001; 38: 247-289, doi: 10.1016/S0165-0173(01)00080-7

12. Davern PJ, Nguyen-Huu TP, La Greca L, Abdelkader A, Head GA. Role of the sympathetic nervous system in Schlager genetically hypertensive mice. Hypertension 2009; 54: 852859, doi: 10.1161/HYPERTENSIONAHA.109.136069.

13. Zhang W, Zhang N, Sakurai T, Kuwaki T. Orexin neurons in the hypothalamus mediate cardiorespiratory responses induced by disinhibition of the amygdala and bed nucleus of the stria terminalis. Brain Res 2009; 1262: 25-37, doi: 10.1016/j.brainres.2009.01.022.

14. Davern PJ, Head GA. Role of the medial amygdala in mediating responses to aversive stimuli leading to hypertension. Clin Exp Pharmacol Physiol 2011; 38: 136-143, doi: 10.1111/j.1440-1681.2010.05413.x.

15. Kubo T, Okatani $H$, Nishigori $Y$, Hagiwara $Y$, Fukumori $R$, Goshima Y. Involvement of the medial amygdaloid nucleus in restraint stress-induced pressor responses in rats. Neurosci Lett 2004; 354: 84-86, doi: 10.1016/j.neulet.2003.09.061.

16. Fukumori R, Nishigori Y, Goshima Y, Kubo T. Contribution of the medial amygdaloid nucleus to the development of hypertension in spontaneously hypertensive rats. Neurosci Lett 2004; 365: 128-131, doi: 10.1016/j.neulet.2004.04.066.

17. Longhurst JC. Neural regulation of the cardiovascular system. In: Squire LR, Blom FE, McConell SK, Roberts JL, Spitzer NC, Zigmond MJ (Editors), Fundamental neuroscience. Burlington: Academic Press; 2008. p 829-853.

18. Veinante P, Freund-Mercier MJ. Distribution of oxytocin- and vasopressin-binding sites in the rat extended amygdala: a histoautoradiographic study. J Comp Neurol 1997; 383: 305325, doi: 10.1002/(SICI)1096-9861(19970707)383:3<305::AIDCNE3 $>3.0 . \mathrm{CO} ; 2-7$.

19. Arakawa H, Arakawa K, Deak T. Oxytocin and vasopressin in the medial amygdala differentially modulate approach and avoidance behavior toward illness-related social odor. Neuroscience 2010; 171: 1141-1151, doi: 10.1016/j.neuroscience. 2010.10.013.

20. Schindler M, Humphrey PP, Emson PC. Somatostatin receptors in the central nervous system. Prog Neurobiol
1996; 50: 9-47, doi: 10.1016/0301-0082(96)00030-5

21. Lu YF, Hattori Y, Moriwaki A, Hayashi Y, Hori Y. Inhibition of neurons in the rat medial amygdaloid nucleus in vitro by somatostatin. Can J Physiol Pharmacol 1995; 73: 670-674, doi: 10.1139/y95-086.

22. Allen Institute for Brain Science. Allen mouse brain atlas. http://mouse.brain-map.org.

23. Wsol A, Cudnoch-Jedrzejewska A, Szczepanska-Sadowska E, Kowalewski S, Dobruch J. Central oxytocin modulation of acute stress-induced cardiovascular responses after myocardial infarction in the rat. Stress 2009; 12: 517-525, doi: 10.3109/10253890802687688.

24. Vela C, Diaz-Cabiale Z, Parrado C, Narvaez M, Covenas R, Narvaez JA. Involvement of oxytocin in the nucleus tractus solitarii on central cardiovascular control: interactions with glutamate. J Physiol Pharmacol 2010; 61: 59-65.

25. Carpentier V, Vaudry $H$, Mallet $E$, Tayot J, Laquerriere A, Leroux $\mathrm{P}$. Ontogeny of somatostatin binding sites in respiratory nuclei of the human brainstem. J Comp Neurol 1997; 381 461-472, doi: 10.1002/(SICl)1096-9861(19970519)381:4<461:: AID-CNE6 $>3.0$. CO;2-0.

26. O'Callaghan EL, Choong YT, Jancovski N, Allen AM. Central angiotensinergic mechanisms associated with hypertension. Auton Neurosci 2013; 175: 85-92, doi: 10.1016/j.autneu.2013. 01.010.

27. Head GA, Mayorov DN. Central angiotensin and baroreceptor control of circulation. Ann N Y Acad Sci 2001; 940: 361-379, doi: 10.1111/j.1749-6632.2001.tb03691.x.

28. Luoh SH, Chan SH. Inhibition of baroreflex by angiotensin II via Fos expression in nucleus tractus solitarii of the rat. Hypertension 2001; 38: 130-135, doi: 10.1161/01.HYP.38.1. 130.

29. Kasparov S, Paton JF. Differential effects of angiotensin II in the nucleus tractus solitarii of the rat--plausible neuronal mechanism. J Physiol 1999; 521 (Part 1): 227-238, doi: 10.1111/j.1469-7793.1999.00227.x.

30. Paxinos G, Watson C. The rat brain in stereotaxic coordinates. San Diego: Academic Press; 1988.

31. Tobaldini E, Montano N, Wei SG, Zhang ZH, Francis J, Weiss RM, et al. Autonomic cardiovascular modulation. IEEE Eng Med Biol Mag 2009; 28: 79-85, doi: 10.1109/MEMB. 2009.934620.

32. Lohman RJ, Liu L, Morris M, O'Brien TJ. Validation of a method for localised microinjection of drugs into thalamic subregions in rats for epilepsy pharmacological studies. J Neurosci Methods 2005; 146: 191-197, doi: 10.1016/j. jneumeth.2005.02.008.

33. Pare D, Royer S, Smith Y, Lang EJ. Contextual inhibitory gating of impulse traffic in the intra-amygdaloid network. Ann N Y Acad Sci 2003; 985: 78-91, doi: 10.1111/j.1749-6632.2003. tb07073.x.

34. Malliani A, Pagani M, Lombardi F, Cerutti S. Cardiovascular neural regulation explored in the frequency domain. Circulation 1991; 84: 482-492, doi: 10.1161/01.CIR.84.2.482.

35. Feuerstein G, Zerbe RL, Faden Al. Central cardiovascular effects of vasotocin, oxytocin and vasopressin in conscious rats. J Pharmacol Exp Ther 1984; 228: 348-353.

36. Roozendaal B, Schoorlemmer GH, Koolhaas JM, Bohus B. Cardiac, neuroendocrine, and behavioral effects of central amygdaloid vasopressinergic and oxytocinergic mechanisms under stress-free conditions in rats. Brain Res Bull 
1993; 32: 573-579, doi: 10.1016/0361-9230(93)90157-7.

37. Grilli M, Raiteri L, Pittaluga A. Somatostatin inhibits glutamate release from mouse cerebrocortical nerve endings through presynaptic sst2 receptors linked to the adenylyl cyclaseprotein kinase A pathway. Neuropharmacology 2004; 46: 388-396, doi: 10.1016/j.neuropharm.2003.09.012.

38. Guzzetti S, Borroni E, Garbelli PE, Ceriani E, Della Bella P, Montano N, et al. Symbolic dynamics of heart rate variability: a probe to investigate cardiac autonomic modulation. Circulation 2005; 112: 465-470, doi: 10.1161/
CIRCULATIONAHA.104.518449.

39. Davern PJ, Chen D, Head GA, Chavez CA, Walther T, Mayorov DN. Role of angiotensin II Type 1A receptors in cardiovascular reactivity and neuronal activation after aversive stress in mice. Hypertension 2009; 54: 1262-1268, doi: 10.1161/HYPERTENSIONAHA.109.139741.

40. Porter K, Hayward LF. Stress-induced changes in C-Fos and corticotropin releasing hormone immunoreactivity in the amygdala of the spontaneously hypertensive rat. Behav Brain Res 2011; 216: 543-551, doi: 10.1016/j.bbr.2010.08.036. 